\title{
Determinants of under- and over- nutrition among reproductive-age women in Bangladesh: trend analysis using spatial modelling
}

\author{
Richa Vatsa ${ }^{1 \&}$, Umesh Ghimire $^{2 \& *}$, Khaleda Yasmin $^{3}$, Farhana Jesmine Hasan $^{4}$ \\ ${ }^{1}$ Central University of South Bihar, SH-7, Gaya Panchanpur Road, Karhara, Post. Fatehpur, Gaya - 824236 (Bihar), \\ India \\ ${ }^{2}$ University of Minnesota, Division of Health Policy and Management, Minneapolis, MN 55455, US \\ ${ }^{3}$ Family Planning-Field Services Delivery, Directorate General of Family Planning, DGFP, Dhaka 1215, Bangladesh \\ ${ }^{4}$ Initiatives for Married Adolescent Girl's Empowerment (IMAGE) project, 9B New Baily Road, Ramna, Dhaka ZC \\ 1200, Bangladesh \\ ${ }^{\&}$ These authors contributed equally to this work.
}

* Corresponding author:

E-mail: creationumesh@gmail.com

https://orcid.org/0000-0002-4246-8379

\begin{abstract}
Bangladesh is facing a double burden of malnutrition which varies spatially and is shifting rapidly over time. The current study aims to analyze the spatial and temporal dependence of under-and over-weight/obesity among Bangladeshi reproductive-age women. The nationally representative cross-sectional data from the Bangladesh Demographic and Health Surveys 2014 and 2017-18 were utilized to study the change in under- and over-weight among 15-49 years women. Bayesian geoadditive regression model was fitted to account for non-linear and linear effects of continuous and categorical covariates and accounted for spatial effects of geographical divisions.

The prevalence of overweight/obese in rural, city corporation and other urban areas has increased significantly over the four-year period from 2014 to 2017-18. Women of the richer and richest categories were more likely to be overweight/obese. Women from Sylhet were more likely to be underweight in both years 2014 and 2017-18, however, the result was also significant for underweight in Mymensingh for the year 2017-18. Women in the Rajshahi and Khulna were more likely to be overweight/obese in 2014. Along with Khulna, women from Barishal and Chittagong were likely to be overweight/obese in the year 2017/18. Underweight and overweight are uneven across the country, with highly urbanized areas overburdened by overweight/obesity. Intervention targeting vulnerable age groups should be a high priority to deal with the increasing burden of obesity.
\end{abstract}




\section{Background}

Under- and over-nutrition is disproportionately prevalent in LMICs, posing enormous challenges in dealing with the global complexities of nutritional problems [1-4]. Malnutrition in its various forms is recognized as an emerging and serious public health concern, resulting in an economic shortfall in both LMICs and developed countries $[5,6]$. Moreover, sustainable development goals (SDGs) targets 2.1 and 2.2 emphasize ensuring access to safe, nutritious, and sufficient food for all people and eradicating all forms of malnutrition [7].

A nutritious diet is required for a healthy and productive human life. However, a variety of factors influence nutritional intake, including insufficient dietary energy intake, poor absorption, and biological use of nutrients as a result of repeated illnesses $[8,9]$. Nevertheless, non-availability of quality diets compounds a higher risk of under-nutrition as well as overweight and obesity. Moreover, sedentary lifestyle, junk food high in sugar and unsaturated fats, and a lack of exercise are all recognized risk factors for overweight/obesity [2,10]. In recent decades, unrestrained demographic and socioeconomic shifts have contributed to a sharp increase in the trend of overweight and obesity in LMICs [3,11]. Due to these risk factors, the exponential rise in non-communicable diseases (NCDs) places South Asian countries under a double burden of malnutrition $[12,13]$.

Bangladesh is divided administratively into eight major divisions and sixty-four districts; There is a significant disparity between the rural and urban Bangladeshi populations (52 percent vs. 22 percent), with 32 percent living below the poverty line (\$US 1.25 per day). Wealth inequality among poor and rich populations is extensive, with the poorest $20 \%$ of the population owning only $9 \%$ of the wealth and primarily residing in cities [14]. Bangladesh, like many other developing countries, has experienced major demographic and epidemiological shifts over the last two decades [15]. Bangladesh's population is expected to exceed 202 million by 2050, a significant increase from 147 million in 2007 [16]. Rapid urbanization, as a result of rapid population growth and migration, causes a shift in the population's dietary habits. The coexistence of under-nutrition and obesity can be catastrophic to the country's already frail health-care system. Findings reveal an increase in the prevalence and risk factors for underweight and overweight/obesity among Bangladeshi women ([17,18]. The National Plan of Action for Nutrition 2016-2025 has envisioned reducing underweight (BMI $<18.5 \mathrm{~kg} / \mathrm{m}^{2}$ ) among adolescent below $15 \%$ and decrease maternal overweight $\left(\mathrm{BMI}>23 \mathrm{~kg} / \mathrm{m}^{2}\right)$ to $30 \%$ [19]. However, the trend of overweight is 2.6 times higher than the last survey conducted a decade ago. According to the latest Bangladesh Demographic and Health Survey 2017-18, under-nutrition among women in Bangladesh was $12 \%$, and the prevalence of overweight/obesity was $32 \%$ [20].

Earlier studies estimated the prevalence and risk factors of BMI while ignoring the multitude of factors that influence its associated covariates. Our study addresses the limitations of previous studies by accounting for the spatial dependence of under- and over-weight/obesity using a Bayesian geoadditive regression method [21,22]. As a result, this method is appropriate for outlining a broad effect of multiple outcomes and can describe the effect of the various types of covariates available. 
The findings of this paper would be useful in guiding and instigating the National Nutrition Plan to understand the current scenarios, trends, and factors affecting under- and over-nutrition among women. Mainly, the use of geospatial analysis shall help through estimating the core assessment of reproductive-age women's nutritional status across several divisions in Bangladesh.

\section{Methods}

Data source and study design

This study relied on two series of Bangladesh Demographic and Health surveys: BDHS 2014 and (BDHS) 2017-18 (IPUMS-DHS) [23]. In collaboration with the National Institute of Population Research and Training in Bangladesh and the United States Agency for International Development, BDHS collects data on several aspects of sociodemographic, fertility, family planning, maternal and child health, and other health and nutrition indicators using a set of standard questionnaires. The BDHS samples were collected from households using a two-stage stratified cluster sampling method. The Primary Sampling Units (PSUs) for the 2014 BDHS were determined using the 2011 national population and housing census. In the BDHS 2014, a total of 17,500 households were interviewed, with a response rate of 98 percent. In contrast, the final data for the BHDS 2017-18 was obtained by interviewing 19,457 households, with a 96.5 percent response rate. More information on the survey and its methodology can be found in the BDHS reports $[20,24]$.

The two major inclusion criteria in the analysis were non-pregnant ever-married women aged 15 to 49 years and women who had given birth two months prior to the survey. After considering these criteria and eliminating 35 missing cases for 'reading newspaper or magazine' (24), 'listening to radio' (1), 'watching television' (1), 'respondent currently working' (5), 'source of drinking water' (3), and 'type of toilet facility' (1), a total of 14997 women from the BDHS 2014 survey data were included in the analysis. Furthermore, 16751 women from the BDHS 2018 survey data were considered in the analysis using the aforementioned inclusion criteria and removing one missing case for 'Listening to radio.'

\section{Dependent variable}

Body Mass Index (BMI) is calculated using the formula weight (in kilograms) divided by height (in metres squared). According to WHO Expert Consultation, 2004 for Asian-specific BMI classification, underweight was defined as having a BMI less than $18.5 \mathrm{~kg} / \mathrm{m}^{2}$, normal as having a BMI of 18.5 to $23.0 \mathrm{~kg} / \mathrm{m}^{2}$, and overweight as having a BMI of 23.0 to $27.5 \mathrm{~kg} / \mathrm{m}^{2}$. Obesity was defined as having a BMI greater than $27.5 \mathrm{~kg} / \mathrm{m}^{2}[25]$.

\section{Independent variables}

The women were asked to complete standard DHS questionnaires on a variety of socio-demographic variables such as place of residence, household wealth status on a five-point scale, education of respondents divided into five categories (no education, primary, secondary, higher, and more), and work status. Household characteristics included in the study were toilet facility (improved/unimproved), water source (protected/unprotected) characterized as per WHO definitions [26], availability of electricity in house (yes/no or not a dejure resident). Women's exposure to mass media such as reading newspapers/magazines, listening to the radio, or watching television, was reported as 'yes' for 
'at least once a week' and 'almost every day', and 'no' for 'not at all' and 'less than once a week'. For spatial analysis, administrative divisions were used, and the continuous variable 'age of women' was considered for possible nonlinear effects on underweight and overweight/obesity among women.

\section{Statistical analysis}

In the equation below, let $y_{i}$ denote the nutritional status of $i^{\text {th }}$ women, with possible categories as 'underweight', 'normal weight', 'overweight/obese', and, $x_{i}$ be the vector of covariates that $y_{i}$ may relate to via a multinomial logit model, defined as,

$$
P\left[y_{i}=r\right]=\frac{\exp \left(\eta_{i, r}\right)}{1+\sum_{s=1}^{K-1} \exp \left(\eta_{i, s}\right)}, r=1:(K-1)
$$

Value $r$ stands for a category of nutritional status; $K$ is the total number of categories. Corresponding to category $\mathrm{r}$, $\eta_{i, r}=u_{i}^{\prime} \beta_{r}+f_{r}\left(z_{i}\right)+g_{r}\left(S_{i}\right), r=1:(K-1)$, with $u_{i}$ as a vector of categorical covariates, $z_{i}$, age, and $S_{i}$, as geographical divisions. The term $\beta_{r}$ relates to linear effects, $f_{r}$, a nonlinear smooth function of age, and $g_{r}$ stands for spatial effects of divisions.

The above mentioned geoadditive regression model is a modification to GLM to account for non-linear effects of continuous covariate, 'age', spatial effects of geographical divisions of the country, and linear effects of other categorical covariates at the same platform [26].

In this study, we followed the Bayesian approach to inference to fit the model. The linear effects $\beta_{r}$ were assigned diffuse priors, $P\left(\beta_{r}\right) \propto$ const. The Bayesian p-spline priors were assumed over the unknown nonlinear smooth function $f_{r}$ [21]. Whereas, Gaussian Markov random field (GMRF) prior was considered over the unknown spatial effects $g_{r}$ [28] A non-informative inverse-gamma hyper-prior (with hyper-parameters $\mathrm{a}=\mathrm{b}=0.001$ as the default setting) was considered over the variance parameter of Bayesian p-spline prior and smoothing parameter of the GMRF prior.

More details on the above geoadditive regression model for categorical response variables may be found in, [29]. The inferences are drawn with MCMC techniques via software BayesX using R-package BayesXSrc. [30]

\section{Results}

Table 1 shows the distribution and trends of background characteristics of reproductive-age women along with pvalues indicating the statistical significance of the change in percentage over the two-survey period. For both surveys, the majority of women lived in rural areas, followed by urban areas. The percentage of urban women increased from 22.56 in 2014 to 26.43 in 2017-18. For both surveys, nearly equal percentages of women (19\%) belonged to the poorest and poorer wealth quintiles, while around $21 \%$ belonged to the richer and richest quintiles. During the twosurvey period, women's educational status improved at all educational levels. Similarly, the percentage of working women increased significantly from $33.65 \%$ in 2014 to $51 \%$ in $2017-18$. 
The percentage of women who had access to safe drinking water decreased slightly. Similarly, access to improved toilet facilities decreased by $4 \%$ during the two surveys. Access to electricity, on the other hand, increased by more than $15 \%$. The percentage of women who read newspapers and listen to the radio also decreased. In comparison to the 2014 survey, three percent more women watched television at least once a week. The percentage of women being underweight declined significantly but there is $10 \%$ increase in women with overweight/obesity. Except for the wealth categories (poorer, middle, richer, and richest), the changes in percentages of characteristics over the two-survey period were significant, as shown with the p-values in Table 1.

Table 1 Frequency distribution of selected characteristics of reproductive age-group women

\begin{tabular}{|c|c|c|c|c|c|}
\hline \multirow[b]{2}{*}{ Variable } & \multicolumn{2}{|c|}{ BHDS 2014} & \multicolumn{2}{|c|}{ BHDS 2017-18 } & \multirow{2}{*}{ p-value } \\
\hline & $\mathrm{N}$ & $(\%)$ & $\mathrm{N}$ & (\%) & \\
\hline \multicolumn{6}{|l|}{ Residence } \\
\hline City Corporation & 1782 & 11.88 & 1630 & 9.73 & $<0.001 * * *$ \\
\hline Other Urban & 3383 & 22.56 & 4428 & 26.43 & $<0.001 * * *$ \\
\hline Rural & 9832 & 65.56 & 10693 & 63.84 & $0.001 * * *$ \\
\hline \multicolumn{6}{|l|}{ Wealth quintile } \\
\hline Poorest & 2774 & 18.5 & 3249 & 19.4 & $0.041 * *$ \\
\hline Poorer & 2841 & 18.94 & 3252 & 19.41 & 0.288 \\
\hline Middle & 3027 & 20.18 & 3273 & 19.53 & 0.150 \\
\hline Richer & 3148 & 21.0 & 3378 & 20.17 & 0.069 \\
\hline Richest & 3207 & 21.38 & 3599 & 21.49 & 0.827 \\
\hline \multicolumn{6}{|l|}{ Educational level } \\
\hline No Education & 3884 & 25.9 & 2980 & 17.79 & $<0.001^{* * *}$ \\
\hline Primary & 4521 & 30.15 & 5579 & 33.31 & $<0.001 * * *$ \\
\hline Secondary & 5356 & 35.71 & 6258 & 37.36 & $0.002 * * *$ \\
\hline Higher & 1236 & 8.24 & 1934 & 11.54 & $<0.001^{* * *}$ \\
\hline \multicolumn{6}{|l|}{ Working Status } \\
\hline No & 9951 & 66.35 & 8185 & 48.86 & $<0.001 * * *$ \\
\hline Yes & 5046 & 33.65 & 8566 & 51.14 & $<0.001 * * *$ \\
\hline \multicolumn{6}{|l|}{ Water Source } \\
\hline Protected & 13942 & 92.97 & 15378 & 91.8 & $<0.001$ *** \\
\hline Unprotected & 1055 & 7.03 & 1373 & 8.2 & $<0.001 * * *$ \\
\hline \multicolumn{6}{|l|}{ Toilet Facility } \\
\hline Improved & 10405 & 69.38 & 10963 & 65.45 & $<0.001 * * *$ \\
\hline Unimproved & 4592 & 30.62 & 5788 & 34.55 & $<0.001^{* * *}$ \\
\hline \multicolumn{6}{|l|}{ Electricity } \\
\hline $\begin{array}{l}\text { No or Not a Dejure } \\
\text { Resident }\end{array}$ & 5753 & 38.36 & 3846 & 22.96 & $<0.001 * * *$ \\
\hline Yes & 9244 & 61.64 & 12905 & 77.04 & $<0.001^{* * *}$ \\
\hline
\end{tabular}




\begin{tabular}{|l|r|r|r|r|l|}
\hline Reads Newspaper & & & & & \\
\hline No & 14078 & 93.87 & 16152 & 96.42 & $<0.001^{* * *}$ \\
\hline yes & 919 & 6.13 & 599 & 3.58 & $<0.001^{* * *}$ \\
\hline Listens to Radio & 14663 & 97.77 & 16465 & 98.29 & $<0.001^{* * *}$ \\
\hline No & 334 & 2.23 & 286 & 1.71 & $<0.001^{* * *}$ \\
\hline yes & & & & & \\
\hline Watches Television & 7344 & 48.97 & 7692 & 45.92 & $<0.001^{* * *}$ \\
\hline No & 7653 & 51.04 & 9059 & 54.08 & $<0.001^{* * *}$ \\
\hline yes & & & & & \\
\hline Nutritional Status & 2730 & 18.2 & 1962 & 11.71 & $<0.001^{* * *}$ \\
\hline Underweight & 6155 & 41.04 & 6294 & 37.58 & $<0.001^{* * *}$ \\
\hline Normal & 6112 & 40.76 & 8495 & 50.71 & $<0.001^{* * *}$ \\
\hline Overweight/obese & & & & & \\
\hline
\end{tabular}

** Significant at level of significance $\leq 0.05$, *** significant at level of significance $\leq 0.01$

\section{Linear Effects}

Table 2 presents the findings of linear association of underweight and overweight/obesity (referenced to the normal weight) with categorical background characteristics of reproductive-age women in Bangladesh. Yet the differences were not statistically significant, women in cities and other urban areas were more likely to be overweight/obese than women in rural municipalities.

Table 2: Posterior estimates for the linear effects of underweight, overweight, and obesity of women of reproductive age-group ( 15 to 49 years)

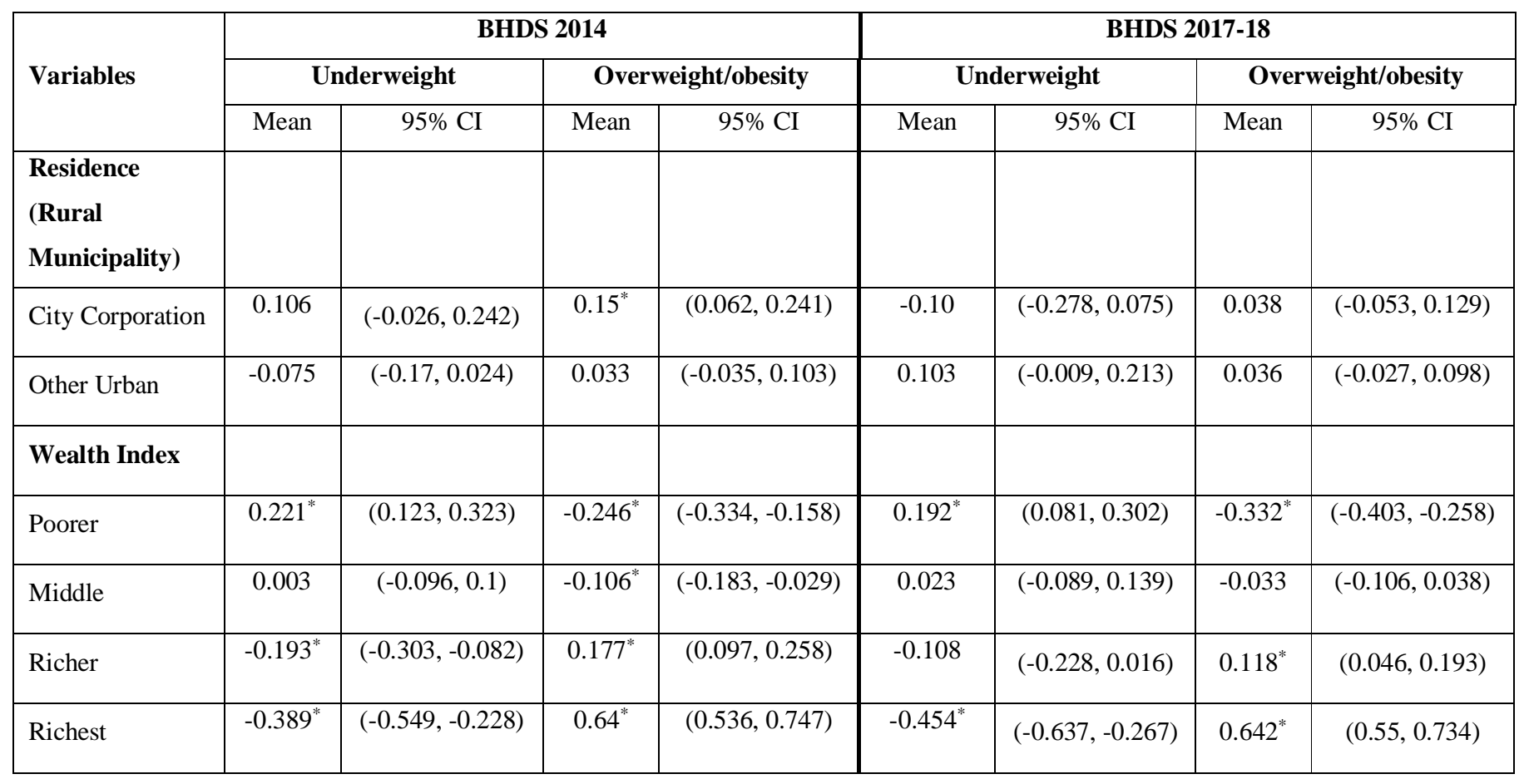




\begin{tabular}{|c|c|c|c|c|c|c|c|c|}
\hline Education & & & & & & & & \\
\hline Primary & $-0.269^{*}$ & $(-0.414,-0.121)$ & $0.464^{*}$ & $(0.346,0.583)$ & $-0.21^{*}$ & $(-0.378,-0.049)$ & $0.477^{*}$ & $(0.363,0.588)$ \\
\hline Secondary & $-0.303^{*}$ & $(-0.586,-0.032)$ & $0.63^{*}$ & $(0.441,0.817)$ & -0.271 & $(-0.532,0.003)$ & $0.508^{*}$ & $(0.349,0.661)$ \\
\hline Higher & $0.713^{*}$ & $(0.292,1.143)$ & $-1.339^{*}$ & $(-1.67,-1.003)$ & $0.514^{*}$ & $(0.038,0.982)$ & $-1.311^{*}$ & $(-1.624,-0.987)$ \\
\hline $\begin{array}{l}\text { Currently } \\
\text { working }\end{array}$ & & & & & & & & \\
\hline Yes & -0.027 & $(-0.076,0.022)$ & $-0.127^{*}$ & $(-0.168,-0.085)$ & 0.013 & $(-0.043,0.068)$ & $-0.12^{*}$ & $(-0.157,-0.084)$ \\
\hline Water sour & & & & & & & & \\
\hline Protected & -0.026 & $(-0.115,0.066)$ & 0.042 & $(-0.046,0.132)$ & 0.047 & $(-0.062,0.154)$ & -0.013 & $(-0.088,0.072)$ \\
\hline Toilet facili & & & & & & & & \\
\hline Improved & -0.049 & $(-0.101,0.006)$ & 0.016 & $(-0.036,0.067)$ & -0.053 & $(-0.114,0.009)$ & 0.032 & $(-0.015,0.075)$ \\
\hline Electricity & & & & & & & & \\
\hline Yes & -0.027 & $(-0.094,0.04)$ & 0.023 & $(-0.039,0.082)$ & 0.007 & $(-0.07,0.077)$ & 0.019 & $(-0.04,0.076)$ \\
\hline $\begin{array}{l}\text { Mass media } \\
\text { newspaper }\end{array}$ & & & & & & & & \\
\hline Yes & $-0.172^{*}$ & $(-0.351,-0.006)$ & $0.181^{*}$ & $(0.089,0.277)$ & 0.151 & $(-0.085,0.377)$ & $0.213^{*}$ & $(0.097,0.33)$ \\
\hline Radio & & & & & & & & \\
\hline Yes & -0.037 & $(-0.208,0.122)$ & -0.11 & $(-0.235,0.02)$ & -0.05 & $(-0.283,0.174)$ & -0.124 & $(-0.259,0.008)$ \\
\hline Television & & & & & & & & \\
\hline Yes & -0.054 & $(-0.114,0.008)$ & $0.137^{*}$ & $(0.088,0.184)$ & -0.044 & $(-0.105,0.018)$ & $0.124^{*}$ & $(0.084,0.165)$ \\
\hline $\begin{array}{l}\text { Model } \\
\text { Diagnostic } \\
\text { DIC }\end{array}$ & \multicolumn{4}{|c|}{26343.3} & \multicolumn{4}{|c|}{29506.9} \\
\hline
\end{tabular}

${ }^{*}$ Significant as mean value is included in the $95 \%$ credible interval, Reference category is Normal weight

According to both surveys, poorer women were more likely to be underweight and less likely to be overweight/obese. Simultaneously, middle-class women were found to be significantly less overweight/obese in the BDHS 2014 survey. Women in the richer and richest wealth categories were more likely to be overweight/obese and less likely to be underweight in both surveys; however, in the BDHS 2017-18 survey, richer wealth category had insignificant effect on underweight. 
The results of the 2014 and 2017-18 surveys in terms of women's education and employment status were consistent. Women with primary and secondary education were less likely to be underweight and more likely to be overweight/obese. Higher educated women were less likely to be overweight/obese, but more likely to be underweight. Likewise, currently working women were significantly less likely to be overweight or obese. Reading newspaper was associated with women being less likely to be underweight in 2014; however, they were more likely to be overweight/obese in both surveys. Similarly, women who watched television were more likely to be overweight or obese, according to the two surveys. While access to water, toilet facilities, and electricity, as well as listening to the radio, were not significantly associated with any form of malnutrition in women.

\section{Spatial Effects}

The posterior mapping of different forms of malnutrition among reproductive-age women in Bangladesh is depicted in Figures 1i(a-d) and 1ii(a-d). According to Fig 1i (a and b), in 2014, women from the Sylhet Division (7) were more likely to be underweight, whereas women from the Khulna Division (4) were less likely to be underweight. Women in Mymensingh Division (5) (previously Dhaka Division (3)) and Sylhet (8) were more likely to be underweight in 2017-18 (Fig 1ii(a, b)). In the same year, women in Barishal Division (1) and Chittagong Division (2) were significantly less likely to be underweight.

In contexts of overweight/obesity, women in the Rajshahi (5) and Khulna (4) regions were more likely to be overweight or obese in 2014. Sylhet (7) women, on the other hand, were less likely to be overweight or obese (Fig $1 \mathrm{i}$ (c and d)). However, in 2017-18, women in Khulna (4), Barishal (1), and Chittagong (2) were more likely to be overweight or obese. Similarly, overweight/obesity was rare in the Sylhet (8) region and Mymensingh (5), which was previously included in Dhaka (3) (Fig 1ii) (c and d). In contrast, the results for BMI in the other divisions were not significant. 
Fig 1(i): Division maps of Bangladesh showing spatial effects of: a) underweight and c) its $95 \%$ CI; b) overweight/obesity and d) its $95 \%$ CI; among reproductive age-group women BDHS 2014

(a)

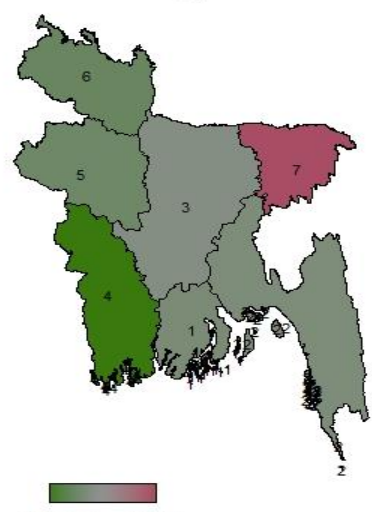

(b)

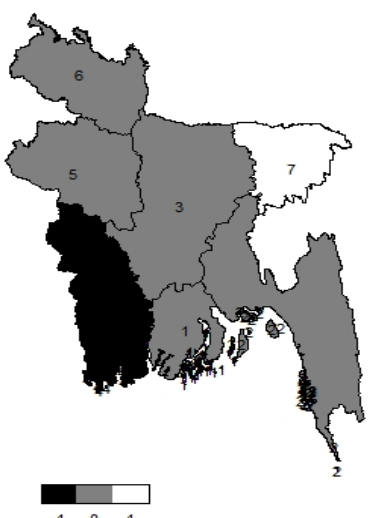

(c)

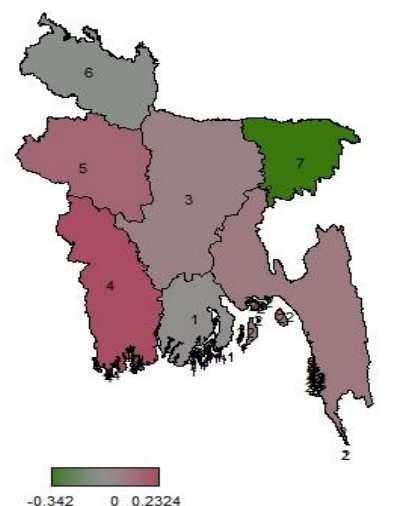

(d)

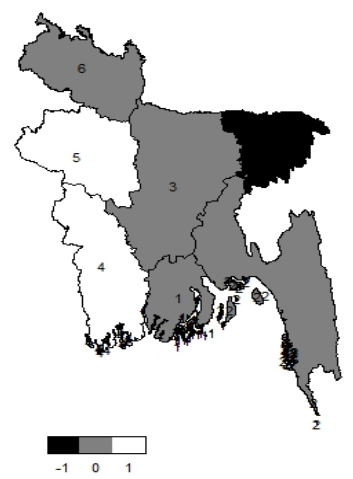

Fig 1(ii): Division maps of Bangladesh showing spatial effects of: a) underweight and c) its 95\% CI; b) overweight/obesity and d) its 95\% CI; among reproductive age-group women BDHS 2017-18

(a)

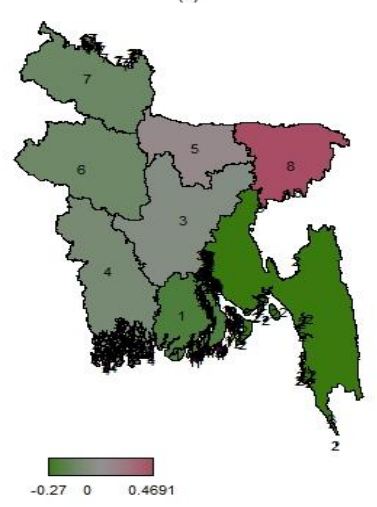

(b)

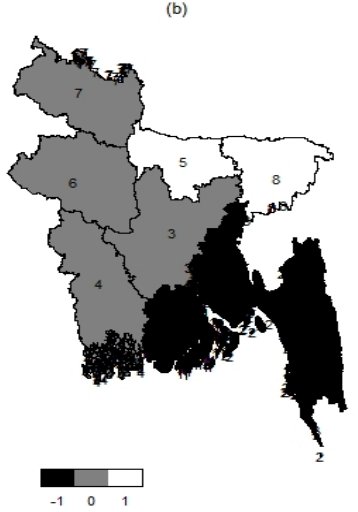

(c)

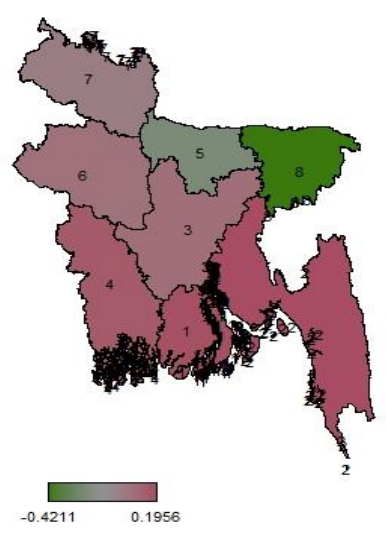

(d)

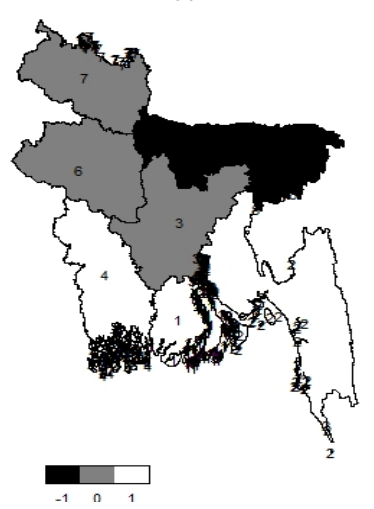

Figure 2 shows the distribution of women's BMI by place of residence for the survey years 2014 and 2017-18. Over the four years from 2014 to 2017-18, the prevalence of underweight in rural, city corporation, and other urban areas decreased. During the same time, however, the rates of overweight/obesity increased in all three residences. 


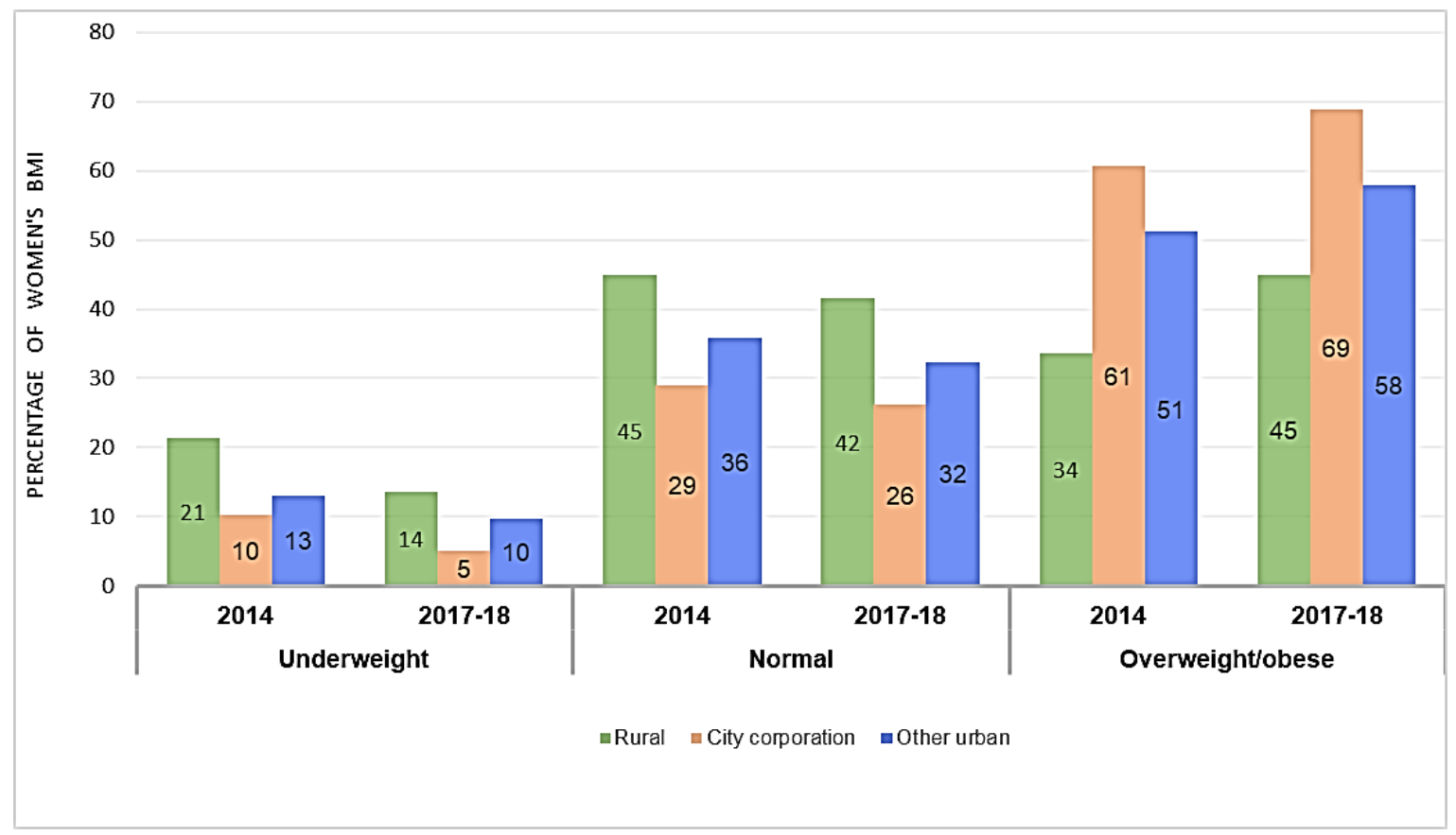

Fig 2: Distribution of underweight, normal weight and overweight/obese according to the place of residence of 15 to 49 years women for the year 2014 and 2017-18 in Bangladesh

\section{Non-linear Effects}

Fig. 3i (a, b) to 3ii (a, b) illustrate the non-linear effects of women's ages on nutritional categories using smooth curves. According to Fig $3 \mathrm{i}$-a and $3 \mathrm{ii}-\mathrm{a}$, for both survey years, women were consistently underweight up to the age of 23 years. After the age of 27, they were less likely to be underweight.

Fig. 3i-b (for the year 2014) shows a steady increase in overweight/obesity around the age of 35, followed by a slight decline. However, in 2017-18, women's overweight/obesity started rising after the age of 35 and peaked around the age of 40, implying that as women aged from 35 to 40, they became more overweight/obese (see Fig. 3iib). However, a slow decrement beyond age 40 was observed for women to be overweight/obese. Furthermore, both surveys' results show that women up to the age of 27 were consistently less overweight or obese. 
Fig 3(i) Nonlinear effects of respondent's age for a) underweight, b) overweight/obesity among reproductive agegroup women in Bangladesh (BDHS 2014)

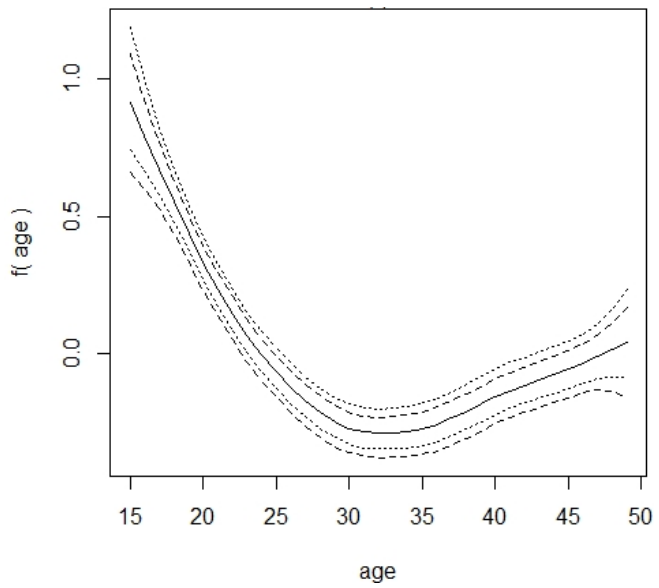

a) Underweight

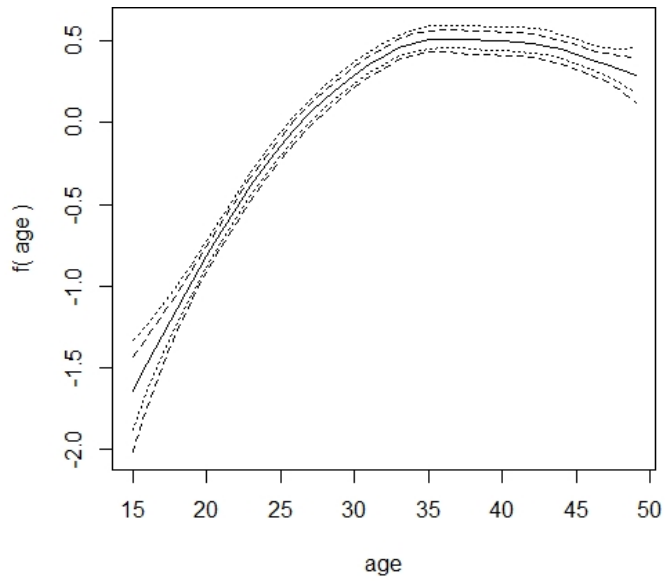

b) Overweight/obesity

Fig 3(ii) Nonlinear effects of respondent's age for a) underweight, b) overweight/obesity reproductive age-group women in Bangladesh (BDHS 2017-18)

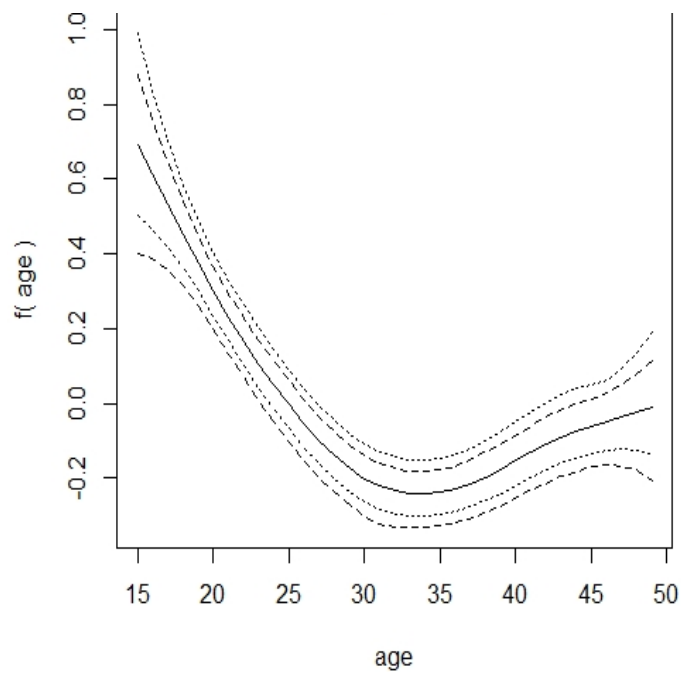

a) Underweight

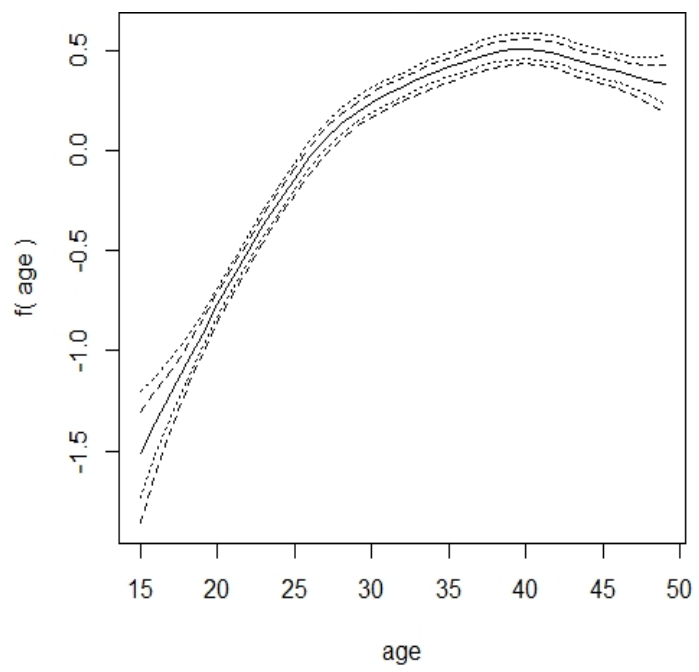

b) Overweight/obesity

\section{Discussion}

The present study examines the determinants of various forms of malnutrition among reproductive-age Bangladeshi women by utilizing a Bayesian geoadditive regression method. Using the Bayesian approach, this first comprehensive study provides constructive evidence by considering the effects of independent variables for underweight, overweight, 
or obesity. Notably, as the findings suggested, demographic determinants such as place of residence, wealth, education attainment, working statuses, as well as access to newsprint and television watching behaviours were associated with underweight, overweight/obesity among Bangladeshi women.

The findings of our study are consistent with previous works [31,32]. From 2014 to 2017-18, the prevalence of underweight among reproductive-age Bangladeshi women decreased, nevertheless, that of overweight/obesity increased significantly, reaching more than 50\%. Other studies have suggested that overweight/obesity rates in Bangladesh have quadrupled from 1996 to 2011. Since 1996, there has been an increase in the prevalence of overweight and a decrease in the prevalence of underweight, particularly among women [33,34]. Likewise, the trend of under-nutrition dropped from 32.22\% in 2004 to $18.29 \%$ in 2014 [32]. Therefore, Bangladesh and other South Asian developing countries (in the same line) have been experiencing a double burden of under-and over-nutrition, prompting a regional rethinking of regional nutrition policy [35,36].

As per our findings for 2014 survey, women in metropolitan are more likely to be overweight/obese. The rapid increase in urban population is one of the potential drivers of unequal distributions of nutritional status, particularly urbancentered overweight [37]. In Bangladesh, the percentage of the population living in urban areas has risen over time (Streatfield and Karar, 2008). The rise in urban population confirms an increase in overweight/obesity in metropolitan and other urbanized areas [39]. Several studies published have repeatedly reported that the rates have risen exponentially, far exceeding the national average (34 percent versus 24 percent) [40]. Moreover, residents in the urban and peripheral areas have easy access to processed food enriched in sugar and unsaturated fat. Globalization, vast investment in food industries, and thriving supermarkets selling energy-dense and junk food at affordable prices have resulted in a shift in food habits and increased unusual bodyweight $[41,42]$. Also, the busy work-life in urban avert people to prepare healthy and home-prepared food. Ultimately, they are more likely to consume fast food that is readily accessible. Unhealthy food habits and sedentary behaviors with no or minimal physical activities may be the key contributors to body mass and the development of non-communicable diseases [43]. A study from Bangladesh reported high rates of overweight/obesity in urban areas compared with rural and increased prevalence of diabetes and hypertension [44]. Evidence-based preventive measures and a strong political commitment would help required to curb the rising prevalence of overweight/obesity. A slow progress in addressing under-nutrition among urban poor and rural populations, as well as widespread urban over-nutrition, have added a systemic burden to the healthcare delivery system in low-middle income countries.

The co-occurrence of under- and over-weight people in a country is a concerning situation that necessitates locationspecific nutrition intervention programmes to address the nutrition issues. Our study findings are consistent with the figures generated by using Asian body mass index cut-offs, which reported co-prevalence of under and over-nutrition in neighbouring countries such as India [45], Myanmar [46], Nepal [36], and Pakistan [47].

Our study aimed to address the division-specific likelihood of women for underweight and overweight. Results indicate that women from Sylhet were more likely to be underweight for both surveys. Overweight/obesity was common among women in Rajshahi and Khulna; however, the likelihood of women being overweight/obese shifted to Khulna, Barishal, and Chittagong in 2017-18. The findings are staggering as changing status of overweight/obesity 
depicts a systemic inability to address the nutrition needs of the region. Therefore, it is essential to scrutinize the regional variation in women's body mass index and identify the local level factors contributing to the unrestrained/high prevalence. Accordingly, imperative actions could be taken for quick improvement in the nutritional status of women across regions.

In line with the literature, our study found that women from lower-income households were more likely to be underweight, while women from higher-income households were more likely to be overweight or obese [17,33,48]. Despite the fact that the wealthy population has better housing than the poor, the wealthy population's lifestyle and eating habits have been drastically changed. To some extent, the richest quintile households tend to consume more calories than they require. Another obvious explanation is that wealthier women buy food from supermarkets and eat out frequently. At the same time, richer households are exposed to readily available cheap, fast food or street food often prepared by adding extra amount of oil and ghee [49]. Regular consumption of such foods contributes to an increase in the risk of being overweight/obese. Contrarily, poor households have limited purchasing power to buy enough food to meet their daily needs. They prefer to eat food prepared at home. Consequently, they are less likely to consume a high-calorie diet. This finding demonstrates the importance of carefully assessing the wealth status of target communities or localities when developing a nutrition programme.

Our study also found differences in the likelihood of being underweight and overweight among women with low and higher education. Having primary or secondary education was linked to less likelihood of being underweight and more likelihood of being overweight/obese. Contrarily, highly educated women were less likely to be overweight/obese. In general, education enables individuals to understand the importance of healthy and nutritious intake and physical fitness. Nevertheless, studies from South Asian countries reported ambiguous results regarding education and women's body mass index. Studies published earlier showed that women with post-secondary education were less likely to be overweight and obese $[35,50]$.

As per our study, working women were less likely to be overweight/obese. It would be worth noting that more than $60 \%$ of the workforce in Bangladesh labor is in low-paid jobs, viz. laborer, factory workers, domestic and manufacturing workers. Mostly, these working women are poor and cannot afford to include adequate nutrition in their everyday meals. Likewise, women working in these low-profile jobs are engaged in intensive physical work, therefore, they have lower chances of being overweight/obese. Access to mass media is vital for receiving information on nutritious diet and healthy practices. Our study findings showed significant association between nutrition outcomes among Bangladehi women with access to newspaper and television. Reading newspaper at least once a week and was watch television at least once a week or/and almost every day was associated with a higher likelihood of being overweight/obese. The role of mass media in acquiring nutrition-related information is undeniable. However, there are limited studies that have assessed the correlation between mass media and nutritional status. Studies from Bangladesh (Aminur Rahman et al., 2019; Rahman et al., 2017) and Ethiopia [52,53] and Nepal [36] reported positive association between television watching and overweight or obesity. Unlike other forms of mass media, television watching is considered a luxury activity and usually spends time in a sitting position. This immobile sedentary activity 
is also linked with the consumption of unheeding eating [54], usually the intake of high caloric and fast food [55]. Besides, commercial advertisements are also one of the influencing factors for purchasing junk foods. [56]

This study has few limitations. Firstly, the analysis of this study is limited to reproductive-age women. Therefore, it cannot be generalized to women beyond this age-group. Secondly, the important individual-level characteristics such as food diversity, diet intake and physical activity which affect women's body mass could not be included in the analysis, since they were not collected in BDHS surveys; Thirdly, the spatial data collected in the BDHS2014 was different from that of BDHS 2017-18. Mymensingh was separated from Dhaka Division on 14 September 2015 [57], which limited us to determine BMI status of women according to the new division of the country for 2017-18 survey. Further, due to the unavailability of a district-level map, in-depth geographic variation of under and overweight could not be assessed.

\section{Conclusion}

In Bangladesh, women faced a double burden of underweight and overweight/obesity, with a significant increase in the prevalence of overweight/obesity in 2017-18 compared to 2014. In Sylhet, women were more likely to be underweight, whereas in Khulna, overweight/obesity was consistently significant in two consecutive surveys. The unabated rise in overweight/obesity among urban women necessitates a radical shift in nutrition interventions to combat its rising rates in highly urbanized cities. Similarly, broader population-level intervention through mass media could be possible to promote eating a nutritious diet, behaviour change, and discourse sedentary activities such as television.

\section{Acknowledgements}

Data for this study was obtained from the IPUMS-DHS. We would like to acknowledge IPUMS-DHS for granting access to datasets for this study. 


\section{References}

1. Bhurosy T, Jeewon R. Overweight and obesity epidemic in developing countries: A problem with diet, physical activity, or socioeconomic status? Scientific World Journal. Hindawi Publishing Corporation; 2014.

2. World Health Organization. Global database on body mass index [Internet]. Wold Health Organization; 2011. Available from: http://apps.who.int/bmi/index.jsp

3. Tzioumis E, Kay MC, Bentley ME, Adair LS. Prevalence and trends in the childhood dual burden of malnutrition in low-and middle-income countries, 1990-2012. Public health nutrition. 2016;19:1375-88.

4. Mamun AA, Finlay JE. Shifting of undernutrition to overnutrition and its determinants among women of reproductive ages in the 36 low to medium income countries. Obesity research \& clinical practice. 2015;9:75-86.

5. World Health Organization. The double burden of malnutrition: Policy Brief. WHO. 2016;12.

6. Nugent R, Levin C, Hale J, Hutchinson B. Economic effects of the double burden of malnutrition. The Lancet. Lancet Publishing Group; 2020. p. 156-64.

7. United Nations. About the Sustainable Development Goals - United Nations Sustainable Development [Internet]. Sustainable Development Goals. 2015. p. 1. Available from:

https://www.un.org/sustainabledevelopment/sustainable-development-goals/

8. James WP. Intestinal absorption in protein-calorie malnutrition. Lancet. 1968;1.

9. Saunders J, Smith T, Stroud M. Malnutrition and undernutrition. Medicine (United Kingdom). 2019.

10. de Onis M, Blossner M, World Health Organization. WHO global database on child growth and malnutrition. Geneva: World Health Organization; 1997.

11. Black RE, Victora CG, Walker SP, Bhutta ZA, Christian P, de Onis M, et al. Maternal and child undernutrition and overweight in low-income and middle-income countries. The Lancet. 2013;382:42751.

12. World Health Organization. The world health report 2002: reducing risks, promoting healthy life. World Health Organization; 2002.

13. World Health Organization. Diet, physical activity and health. World Health Organization,(documents A55/16 and A55/16 Corr. 1). Geneva: World Health Organization; 2002.

14. Bangladesh Bureau of Statistics. Report of the Household Income and Expenditure Survey 2010 [Internet]. Dhaka; 2010. Available from:

http://203.112.218.65:8008/WebTestApplication/userfiles/Image/LatestReports/HIES-10.pdf

15. Karar ZA, Alam N, Streatfield PK. Epidemiological transition in rural Bangladesh, 1986-2006. Global Health Action. 2009;2.

16. United Nations. Revision of World Population Prospects 2017. United Nations Press Release. 2017;

17. Aminur Rahman M, Mosfequr Rahman M, Mosiur Rahman M, Jesmin SS. The double burden of under- And overnutrition among Bangladeshi women: Socioeconomic and community-level inequalities. PLoS ONE. 2019;14. 
18. Biswas T, Garnett SP, Pervin S, Rawal LB. The prevalence of underweight, overweight and obesity in Bangladeshi adults: Data from a national survey. PloS one [Internet]. San Francisco: Public Library of Science; 2017;12:e0177395. Available from: http://syddansk.summon.serialssolutions.com/2.0.0/link/0/eLvHCXMwfV1Lb9NAEF5BKiEkVNHwaEp b7Q2QcBo_sra5oKQ0KqKqeqAXLqt9tlGpbeykkP_BD2ZmvQ4Kolwsy2t77Z3xzOys5_sliaPhKPjLJmiR hIkMMQMp01THkU4EzI6kFeAurCNVuDyLzqfx53NEGPrVlcZ4cXdW0pluXSrMmhFGfpW8NDsQ_U9QB4pXG_tSD

19. Ministry of Health and Family Welfare. National Plan of Action for Nutrition 2016-2025. Dhaka, Bangladesh; 2017.

20. ICF/NIPORT. Bangladesh Demographic and Health Survey 2017-18 [Internet]. Dhaka, Bangladesh: NIPORT/ICF; 2020. Available from: https://www.dhsprogram.com/pubs/pdf/FR344/FR344.pdf

21. Fahrmeir L, Kneib T, Lang S. Penalized structured additive regression for space-time data: a Bayesian perspective. Statistica Sinica. 2004;731-61.

22. Belitz C, Brezger A, Kneib T, Lang S, Umlauf N. BayesX-Software for Bayesian inference in structured additive regression models. Version; 2009.

23. Heger Boyle E, King M, Sobek M. IPUMS Demographic and Health Surveys. Version 8 [dataset]. Minneapolis, MN: IPUMS and ICF. 2020.

24. NIPORT/Bangladesh NI of PR and T-, Associates M and, International ICF. Bangladesh Demographic and Health Survey 2014 [Internet]. Dhaka, Bangladesh: NIPORT, Mitra and Associates, and ICF International; 2016. Available from: http://dhsprogram.com/pubs/pdf/FR311/FR311.pdf

25. WHO Expert Consultation. Appropriate body-mass index for Asian populations and its implications for policy and intervention strategies. Lancet (London, England). 2004;363:157-63.

26. WHO and UNICEF. Progress on Drinking Water, Sanitation and Hygiene: 2017 Update and SDG Baseline. World Health Organization. 2017;

27. Lang S, Brezger A. Bayesian P-splines. Journal of computational and graphical statistics. 2004;13:183-212.

28. Rue H, Held L. Gaussian Markov random fields: theory and applications. CRC press; 2005.

29. Kneib T, Fahrmeir L. Structured additive regression for categorical space-time data: A mixed model approach. Biometrics. 2006;62.

30. Christiane Belitz, Andreas Brezger, Thomas Kneib, Stefan Lang NU. BayesX: Software for Bayesian Inference in Structured Additive Regression Models [Internet]. 2017. Available from: http://www.bayesx.org/

31. Shafique S, Akhter N, Stallkamp G, de Pee S, Panagides D, Bloem MW. Trends of under- and overweight among rural and urban poor women indicate the double burden of malnutrition in Bangladesh. International Journal of Epidemiology. 2007;

32. Chowdhury MAB, Adnan MM, Hassan MZ. Trends, prevalence and risk factors of overweight and obesity among women of reproductive age in Bangladesh: a pooled analysis of five national crosssectional surveys. BMJ open. British Medical Journal Publishing Group; 2018;8:e018468. 
33. Hoque ME, Long KZ, Niessen LW, al Mamun A. Rapid shift toward overweight from double burden of underweight and overweight among Bangladeshi women: A systematic review and pooled analysis. Nutrition Reviews. 2015;73.

34. Biswas RK, Rahman N, Khanam R, Baqui AH, Ahmed S. Double burden of underweight and overweight among women of reproductive age in Bangladesh. Public Health Nutrition. 2019;22.

35. Bhandari P, Gayawan E, Yadav S. Double burden of underweight and overweight among Indian adults: spatial patterns and social determinants. Public Health Nutrition [Internet]. Cambridge University Press; 2021 [cited 2021 Jun 13];1-15. Available from: https://www.cambridge.org/core/product/identifier/S1368980021001634/type/journal_article

36. Ghimire U, Vatsa R. Spatial distribution of various forms of malnutrition among reproductive age women in Nepal: a Bayesian geoadditive quantile regression approach. SSM - Population Health. Elsevier BV; 2021;14:100781.

37. Rachmi CN, Li M, Baur LA. Overweight and obesity in Indonesia: prevalence and risk factors - a literature review. Public Health. Elsevier; 2017;147:20-9.

38. Streatfield PK, Karar ZA. Population challenges for Bangladesh in the coming decades. Journal of Health, Population and Nutrition. 2008;26.

39. Barry M Popkin. Global nutrition dynamics: the world is shifting rapidly toward a diet linked with noncommunicable diseases | The American Journal of Clinical Nutrition | Oxford Academic. The american journal of clinical nutrition. 2016.

40. Tanwi TS, Chakrabarty S, Hasanuzzaman S, Saltmarsh S, Winn S. Socioeconomic correlates of overweight and obesity among ever-married urban women in Bangladesh. BMC Public Health. 2019;19.

41. FAO. The state of Food Security and Nutrition in the World. Transforming Food Systems for Affordable Healthy Diets. FAO. 2020.

42. Popkin BM. Technology, transport, globalization and the nutrition transition food policy. Food Policy. 2006;31.

43. Malik VS, Willett WC, Hu FB. Global obesity: Trends, risk factors and policy implications. Nature Reviews Endocrinology. 2013.

44. Biswas T, Townsend N, Islam MS, Islam MR, Gupta R das, Das SK, et al. Association between socioeconomic status and prevalence of non-communicable diseases risk factors and comorbidities in Bangladesh: findings from a nationwide cross-sectional survey. BMJ open. British Medical Journal Publishing Group; 2019;9:e025538.

45. Little M, Humphries S, Patel K, Dewey C. Factors associated with BMI, underweight, overweight, and obesity among adults in a population of rural south India: A crosssectional study. BMC Obesity. $2016 ; 3$.

46. Hong SA, Peltzer K, Lwin KT, Aung LS. The prevalence of underweight, overweight and obesity and their related socio-demographic and lifestyle factors among adult women in Myanmar, 2015-16. PloS one. 2018;13. 
47. Janjua NZ, Mahmood B, Bhatti JA, Khan MI. Association of household and community socioeconomic position and urbanicity with underweight and overweight among women in Pakistan. PloS one. 2015/04/04. 2015;10:e122314.

48. Bishwajit G. Household wealth status and overweight and obesity among adult women in Bangladesh and Nepal. Obesity Science and Practice. 2017;

49. Khairuzzaman M, Chowdhury FM, Zaman S, al Mamun A, Bari ML. Food safety challenges towards safe, healthy, and nutritious street foods in Bangladesh. International Journal of Food Science. 2014.

50. Ohlsson B, Manjer J. Sociodemographic and Lifestyle Factors in relation to Overweight Defined by BMI and "normal-Weight Obesity." Journal of Obesity. 2020;2020.

51. Rahman M, Islam MRJ, Haque SE, Saw YM, Haque MN, Duc NHC, et al. Association between highrisk fertility behaviours and the likelihood of chronic undernutrition and anaemia among married Bangladeshi women of reproductive age. Public Health Nutrition. 2017;20.

52. Ahmed M, Seid A, Kemal A. Does the Frequency of Watching Television Matters on Overweight and Obesity among Reproductive Age Women in Ethiopia? Journal of Obesity. 2020;2020.

53. Tekalegn Y. Determinants of Overweight or Obesity among Men Aged 20-59 Years: A Case-Control Study Based on the 2016 Ethiopian Demographic and Health Survey. Journal of Obesity. 2021.

54. Wansink B. From mindless eating to mindlessly eating better. Physiology and Behavior. 2010.

55. Ng SW, Popkin BM. Time use and physical activity: A shift away from movement across the globe. Obesity Reviews. 2012;

56. Foster JA, Gore SA, West DS. Altering TV viewing habits: An unexplored strategy for adult obesity intervention? American Journal of Health Behavior. 2006.

57. dnews24.com. Govt gives final approval for Mymensingh as country's eighth administrative division. dnews24.com [Internet]. Dhaka, Bangladesh; Available from:

https://bdnews24.com/bangladesh/2015/09/14/govt-gives-final-approval-for-mymensingh-as-country-seighth-administrative-division 